His suggestions for providing the Third World with technology on better terms, for cooperation with the developing countries in the transfer and adaptation of technologies, and for the indigenous development of appropriate technologies are more positive and complete.

The God That Limps is a timely and stimulating book. In warning of the need to recognize that technology cannot of itself solve social and political problems Colin Norman allows a much greater role for technology than Jay Forrester, who recently asked whether for the past 200 years technology has done much more than cope with the consequences of population growth.

Sir Bruce Williams is Director of The Technical Change Centre, London, and Visiting Professor at Imperial College, University of London.

\title{
Meteorology enters the mesoscale era
}

\section{Edward J.Zipser}

Meso-scale Atmospheric Circulations. By B. W. Atkinson. Pp.495. ISBN 0-12-065960-3. (Academic: 1981.) £32.40, $\$ 78$.

FIFTY years hence, it may be difficult to explain to students how most meteorologists contrived to postpone to the 1980 s their discovery of the importance of the mesoscale, the intermediate scales of motion. Indeed, how could so many observers of the natural world have accepted for so long that local weather events were controlled by large-scale systems with a spectral gap in the mesoscale (tens to hundreds of kilometres)? While better observations and numerical models have improved forecasts on time scales of 1-3 days, our ability to forecast 1-12 hours into the future, or to anticipate severe weather or flooding rains, has stagnated for 20 years.

Atkinson has written the first book in mesoscale meteorology, and his pioneering effort sets a high standard. He has made eminently reasonable selections of what to include and what to exclude. Each subject is treated in a similar manner, with observational knowledge summarized first, followed by theories, numerical simulation results and, where applicable, hardware models.

Many of the subjects have never been summarized comprehensively before. The first half of the book is a superb, systematic review of topographically induced flows, including lee waves, downslope winds, seaand land-breeze circulations, and slope and valley wind circulations. The literature has been surveyed exhaustively; numerous papers hitherto unknown to this reviewer are placed in context and, where appropriate, recent papers highlighted. It will be difficult to improve upon this treatment, and Atkinson's book could well become the classic reference work on these subjects for the next 20 years.

Severe local storms have been the centrepiece of mesoscale meteorology for many years. Storms which generate hail, tornadoes and other damaging winds are challenging subjects because they are intrinsically scale-interaction phenomena. The severe storms chapter is excellent on convective storms in general, and in summarizing recent literature on hailstorms, but it is rather weak on the rotational aspects and on recent literature on tornadic storms. The recent work on squall lines is well-covered, but it should have been clearly separated from the severe storms chapter and placed in a section on mesoscale convective systems, which are larger than individual storms. By not distinguishing between organized convection and severe convection, as where squall lines are claimed to be severe by definition, Atkinson's book will help some long-held misconceptions to persist for a few more years.

After a useful chapter largely concerned with recent results on shallow cellular circulations, the book closes by treating mesoscale circulations within cyclones. Atkinson himself has made contributions to extratropical cyclone studies, and this section is strong. Because this type of research concentrates upon radar description of precipitation distribution, however, it may not be obvious to all readers when it is proper to make inferences about mesoscale wind circulations in the absence of direct measurements. In addition, the section on tropical cyclones, like the literature on which it is based, is somewhat uneven. The recent improvement in aircraft instrumentation should lead to the need to update this section in the near future. For unknown reasons, no mention is made of cyclonic circulations in the tropics other than tropical storms.

This book does not attempt to be all things to all people; it deals with basic science, not applied science. The sea breeze, for example, is treated as a basic fluid flow, and the importance of that flow for precipitation distribution and air quality, although mentioned, is covered either briefly or not at all.

The author can take pride in fulfilling a long-standing need for a text in mesoscale meteorology, which is sure to stand as a basic reference work for decades. Nearly all meteorologists will want a copy close at hand.

Edward J. Zipser is a Senior Scientist in the Convective Storms Division at the National Center for Atmospheric Research, Boulder, Colorado. (NCAR is sponsored by the National Science Foundation.)

\section{People and change}

\section{William Brass}

Population and Technology. By Ester Boserup. Pp.225. UK ISBN 0-631-12817-4 (Basil Blackwell: 1981); US ISBN 0-22606673-8 (University of Chicago Press: 1981.) £12.50, $\$ 17.50$.

IN the early 1960s Ester Boserup began to propagate the view that population growth was one of the fundamental causes of the development of new agricultural methods. The importance of her work was less in the idea than in the lucidity and coherence of the demonstration. The present book is a wider essay on a similar theme, the interaction of population growth and technological change.

The central idea is that population factors have been a major determinant of the introduction of (or failure to exploit) new methods for the organization and improvement of production. Since the scope of the book is the whole of human history, much of it is logically concerned with agricultural output. The presentation is not of a highly structured argument from the idea to the consequences; rather there is an extensive historical review beginning with the transition from hunting-gathering to agriculture, and ending with the population-technological relationships in the less-developed countries of the present day. In between there are accounts of the establishment of urban civilizations, with particularly interesting sections on Mesopotamia, the Maya and China, the development of trade and industry in Europe, mass-migration to the United States and elsewhere, the transfer of industrial technologies to Asia and much else. Despite the unifying theme there is no dogmatism; population growth may be taken as the driving force but the importance of effects in the reverse direction is implicitly accepted.

Again and again in traditional works of pre-history and history there is a sentence which states that as a consequence of technological change (settled agriculture, spread of the use of iron, industrial invention) the population grew. There is seldom even a cursory consideration of how this happened; the way in which the changes could have altered fertility and/or mortality appropriately is left obscure. The large increase in the knowledge of the basic demography of less-developed communities in recent years has intensified the difficulty of the explanation. No simple, universal link between technological development and reduced mortality or increased fertility can be demonstrated.

The God that Limps: Science and Technology in the Eighties, by Colin Norman (reviewed on page 871 ) will be published in Great Britain on 26 May 1982. 